\title{
Bolsa Família, informação e preconceito: uma análise com o uso de experimentos
}

Pedro Santos Mundim

Universidade Federal de Goiás (UFG)

Robert Vidigal

Stony Brook University

Fernando Canto Michelotti

Ministério da Saúde (MS)

André Jácomo de Paula Pinto

Instituto Brasileiro de Pesquisa e Análise de Dados (Ibpad)

Este artigo apresenta e discute os resultados de experimentos de lista e de informação realizados em pesquisas de opinião pública encomendadas pela Secretaria de Comunicação Social da Presidência da República, em 2014 e 2015. Com o experimento de lista, buscavase captar e estimar um suposto preconceito latente em relação ao Programa Bolsa Família (PBF) e seus beneficiários; e, com os experimentos de informação, avaliar quais mensagens sobre os resultados positivos do programa seriam mais eficientes para mudar opiniões do público em relação a ele e aumentar o seu apoio junto à população brasileira. Até onde sabemos, essas foram umas das poucas vezes em que se utilizaram tais técnicas de pesquisa na elaboração de estratégias de comunicação do Governo Federal. Mas, ao contrário do que se esperava, encontrou-se um apoio latente ao PBF, e não uma rejeição, e as informações repassadas aos entrevistados não foram capazes de alterar suas opiniões.

Palavras-chave: Programa Bolsa Família, experimento de lista, experimento de informação

[Artigo recebido em 28 de abril de 2018. Aprovado em 31 de outubro de 2019.] 


\section{Bolsa Familia, información y prejuicio: un análisis con el uso de experimentos}

Este artículo presenta y discute los resultados de experimentos de lista y de información realizados en encuestas de opinión pública encargadas por la Secretaría de Comunicación Social de la Presidencia de la República, en 2014 y 2015. Con el experimento de lista, se buscaba captar y estimar un supuesto preconcepto latente en relación al Programa Bolsa Familia (PBF) y sus beneficiarios; y, con los experimentos de información, evaluar qué mensajes sobre los resultados positivos del programa serían más eficientes para cambiar opiniones del público en relación a él y aumentar su apoyo junto a la población brasileña. Hasta donde sabemos, esas fueron unas de las pocas veces en que se utilizaron tales técnicas de investigación en la elaboración de estratégicas de comunicación del Gobierno Federal. Pero, al contrario de lo que se esperaba, se encontró un apoyo latente al PBF, y no un rechazo, y las informaciones repasadas a los entrevistados no fueron capaces de alterar sus opiniones.

Palabras clave: Programa Bolsa Familia, experimento de lista, experimento de información

\section{Bolsa Família, information and prejudice: an analysis using experiments}

This article presents and discusses the results of a list and information experiments carried out in public opinion surveys commissioned by the Secretariat of Social Communication of the Presidency of the Republic in 2014 and 2015. The list experiment sought to capture and estimate a supposed latent prejudice in relation to the Bolsa Família Program (PBF) and its beneficiaries. The information experiments sought to evaluate which messages about the positive results of the program would be more efficient to change public opinion about it and to increase its support amongst the Brazilian population. As far as we know, these were one of the few times in which such research techniques were used in the communication strategies elaboration of the Federal Government. However, and contrary to expectations, there was a latent support for the PBF, not a rejection, and the information passed on to interviewees was not able to change their opinions.

Keywords: Bolsa Família Program, list experiment, information experiment 
Uma das consequências da vitória da ex-presidente Dilma Rousseff (PT) na disputada eleição de 2014 foi a proliferação de manifestações preconceituosas relativas ao Programa Bolsa Família (PBF) e seus beneficiários. Essas declarações ocorreram, principalmente, nas redes sociais e programas de troca de mensagens instantâneas como Facebook, Twitter e WhatsApp. Beneficiários do programa e moradores das regiões mais pobres do país, especialmente o Nordeste, foram hostilizados por eleitores descontentes com a reeleição da petista. Embora muitas das falas ofensivas contra o PBF não fossem novidade no Brasil (CAMPello, 2013; Rego; PInZANI, 2013), até 2014 parecia haver um certo pudor em lançá-las no espaço público, já que o programa toca em um tema sensível, que é o combate à pobreza.

Tal contexto fez surgir no Ministério do Desenvolvimento Social (MDS) - órgão responsável pelo PBF e que atualmente compõe o Ministério da Cidadania - uma preocupação em torno do grande volume de circulação dessas mensagens negativas. Por esse motivo, a Assessoria de Pesquisa de Opinião Pública da Secretaria de Comunicação Social da Presidência da República (Secom/PR) incluiu um bloco de perguntas sobre o PBF na pesquisa de opinião pública quadrimestral de novembro de 2014. Entre elas estava um experimento de lista para investigar a existência de um preconceito latente em relação ao programa e seus beneficiários que, por conta do resultado da eleição de 2014, tornara-se manifesto.

Ao mesmo tempo, interessava ao MDS não apenas identificar a real distribuição das opiniões dos brasileiros sobre o PBF, mas também lançar uma campanha publicitária sobre o programa e suas principais realizações. Os objetivos seriam: aumentar o apoio ao PBF e conscientizar e combater as falas preconceituosas, principalmente contra os beneficiários.

$\mathrm{Na}$ época, a Secom/PR era responsável por produzir e veicular, através das agências contratadas, peças publicitárias sobre as ações do Governo Federal. Como os recursos da União são finitos, optou-se por testar quais tipos de informação poderiam ser bem-sucedidos na tentativa de sensibilizar, ou até mesmo mudar, a opinião das pessoas sobre o PBF, suas realizações e seus beneficiários. Por isso, foram realizados experimentos de informação em duas rodadas de pesquisa telefônicas nos meses de junho e julho de 2015 . $^{1}$

Com este artigo buscamos, justamente, apresentar e discutir os resultados de ambos os experimentos - de lista e de informação - realizados pela Assessoria

\footnotetext{
${ }^{1}$ Três dos autores deste artigo trabalhavam na Assessoria de Pesquisa de Opinião Pública da Secom/PR na época em que aconteceram os fatos narrados na introdução deste artigo. Daí a descrição pormenorizada dos motivos que levaram esse órgão do Governo Federal a incluir nas suas pesquisas as perguntas sobre o Bolsa Família, além da realização dos experimentos
} 
de Pesquisa de Opinião Pública da Secom/PR, voltados para captar o suposto preconceito latente em relação ao PBF e quais mensagens seriam mais eficientes para aumentar o apoio ao programa junto à opinião pública brasileira. As hipóteses por trás de cada um deles eram as seguintes: no caso do experimento de lista, de que havia um preconceito latente em relação ao PBF e beneficiários; e no caso dos experimentos de informação, de que a exposição a dados sobre os resultados positivos do programa levaria as pessoas a mudarem suas opiniões em relação ao programa. Até onde sabemos, essas foram umas das poucas vezes em que se buscou utilizar tais técnicas de pesquisa na elaboração de estratégias de comunicação do Governo Federal.

O artigo está organizado da forma descrita a seguir: no próximo item, discutimos duas questões relacionadas ao uso de experimentos em pesquisas de opinião pública, que é como eles permitem aos pesquisadores superar as dificuldades de lidar com temas sensíveis, e como o recebimento de informações específicas sobre o resultado de políticas públicas afeta os julgamentos políticos. Em seguida, apresentamos o contexto em que as pesquisas foram conduzidas e a descrição dos dados utilizados. Finalmente, discutimos os surpreendentes resultados dos experimentos: ao contrário do que se esperava, encontrouse um apoio latente ao PBF, e não uma rejeição ao programa. Além disso, as informações repassadas às pessoas entrevistadas não foram capazes de alterar suas opiniões.

\section{O uso de experimentos em pesquisas de opinião pública}

Em Designing Social Inquiry, King, Keohane e Verba (1994) enfatizaram que o principal objetivo da ciência é fazer inferências causais. Uma das formas mais adequadas de realizá-las é através de experimentos, que Druckman et al. (2011a, p. 4) definiram como "um teste deliberado de uma proposição causal" que pesquisadores utilizam para "avaliar os impactos causais de variáveis explicativas". Apesar disso, apenas a partir dos anos 1970, a Ciência Política passou a fazer uso mais frequente de experimentos (DRUCKMAN et al., 2011a). Até esse período, como ressaltou Kinder (2011, p. 526), eles eram vistos "por grande parte do establishment da ciência política como exóticos ou irrelevantes".

Ao permitir uma distribuição aleatória de observações entre grupos de controle e tratamento (DRUCKMAN et al., 2006), os experimentos permitem chegar o mais próximo possível da relação de causalidade investigada (HoLLAND, 1986), pois qualquer estimativa de efeito encontrada somente terá ocorrido em função do tratamento imposto pelo pesquisador. Isso é importante porque, muitas vezes, a 
correlação entre duas variáveis não possui uma clara direção de causalidade, o que leva a questionamentos sobre as inferências (DRUCKMAN et al., 2011b).

Hoje, pode-se dizer que o uso de experimentos está difundido nas diversas áreas que compõem as Ciências Sociais e Humanas, com um papel de destaque entre os cientistas políticos (Druckman et al., 2011a; KInder; PAlfreY, 1993a). Talvez seja por esse motivo que os estudos sobre comunicação política e efeitos da mídia, que fizeram uso dessa técnica, alcançaram resultados importantes.

Por exemplo, lyengar e Kinder (1987) e Ansolabehere e Iyengar (1995) mostraram, através de experimentos controlados, efeitos de agendamento, primimg e enquadramento na opinião dos eleitores norte-americanos. Gerber, Karlan e Bergan (2009) utilizaram um experimento de campo (GERBER, 2011) para atestar o efeito da cobertura de jornais impressos no comportamento dos eleitores. Eles selecionaram aleatoriamente três grupos de indivíduos de um condado no Estado de Virgínia (EUA). Para dois deles foi oferecido, por dez dias, uma assinatura gratuita do Washington Post, de inclinação liberal, e do Washington Times, de inclinação conservadora. $^{2} \mathrm{O}$ terceiro grupo foi o controle. Dados coletados posteriormente mostraram que mesmo essa breve exposição aos jornais afetou a decisão do voto e o comparecimento eleitoral.

No Brasil, Porto (2007) identificou efeitos de enquadramento na forma como telespectadores davam sentido à realidade política, seja ao se exporem ao noticiário tradicional, seja a programas populares de entretenimento, como as telenovelas. Embora possa-se questionar a validade externa dos experimentos controlados (IYENGAR, 2011), pesquisas posteriores atestaram em grande medida esses achados (Azevedo, 2004; Nelson; Bryner; Carnahan, 2011; Porto, 2004).

\section{Os experimentos de lista e de informação}

Um dos problemas das pesquisas de opinião pública ao tratar de temas sensíveis é que muitos respondentes podem se sentir constrangidos de falar abertamente o que realmente pensam. Isso significa que os resultados agregados da pesquisa serão enviesados, já que os respondentes sobrestimam, ou subestimam, determinadas opiniões e omitem seu real posicionamento através de uma não resposta (BERINSKY, 1999, 2002; TOURANGEAU; YAN, 2007). Uma das formas de minimizar esse problema é através de experimentos de lista (JANUS, 2010; KANE; CRAIG; WALD, 2004; KUKLINSKI et al., 1997; KUKLINSKI; CobB; GIlens, 1997; RedLAWSK; TOlberT; Franko, 2010; Streb et al., 2008; TURGEON; CHAVES; WIVES, 2014; VIDIGAL, 2018), que permitem

\footnotetext{
${ }^{2} \mathrm{Na}$ descrição dos resultados de pesquisas realizadas nos EUA, mantivemos o entendimento contextual dos termos liberal e conservador que implica, respectivamente, ser de esquerda e ser de direita.
} 
estimar o quanto as pessoas realmente escondem sua verdadeira opinião, sem que se sintam constrangidas pela pergunta ou pela presença do entrevistador. ${ }^{3}$

Em dois estudos sobre questões raciais, Kuklinski e colaboradores (KUKLINSKI et al., 1997; KUKLINSKI; СOBB; GILENS, 1997) demonstraram a existência de preconceitos e de rejeição a políticas de ação afirmativa a favor dos negros norte-americanos. Essas opiniões estavam latentes ou escondidas pelo efeito de desejabilidade social (TURGEON; ChAVES; WIVES, 2014, p. 366), que é quando os respondentes "tendem a sub ou sobreinformar suas preferências em pesquisas por medo de não se adequarem às normas sociais".

Encontrou-se efeito semelhante na pesquisa de Streb et al. (2008). Pesquisas de opinião pública mostravam que cerca de $90 \%$ dos entrevistados votariam numa mulher para presidente, caso ela estivesse qualificada para o cargo. Mas, com um experimento de lista, descobriu-se que esse número era menor. Aproximadamente $26 \%$ dos respondentes expressaram raiva sobre uma presidente do sexo feminino, um exemplo da ocorrência de efeito de desejabilidade social. ${ }^{4}$

Desde meados do século passado, sabe-se que a maioria dos eleitores não se interessa e tem baixo nível de informação sobre política (CAMPBEL et al., 1967; LAZARSFELD; BERELSON; GAUDET, 1948). Isso levou cientistas políticos a questionarem se informação adicional faz ou não diferença para as decisões políticas e opiniões dos cidadãos. Ambas as perguntas são importantes porque as distribuições das preferências dos indivíduos podem ser usadas pelos governantes para decidirem se apoiam e implementam uma política pública (HASENFELD; RAFFERTY, 1989; MANZA; COOK, 2002; TURGEON; RENNó, 2010).

Vários estudos foram feitos sobre o assunto. De um lado, estão pesquisadores que defendem que os cidadãos conseguem tomar boas decisões com o uso de atalhos informacionais e mecanismos heurísticos (LUPIA, 1994; LUPIA; MCCUBBINS, 2000; POPKIN, 1991, 1993); ou que, no agregado, a opinião pública se comporta de maneira bastante razoável, pois os erros individuais causados pela falta de informação são cancelados a partir do milagre da agregação (PAGE; SHAPIRO, 1992). De outro lado, estão aqueles que defendem que a informação adicional faz diferença (Althaus, 1998; BARTELS, 1996; LUSKIN; FISHKIN; JOWELL, 2002). Os experimentos têm dado razão a esse segundo grupo.

\footnotetext{
${ }^{3}$ Uma apresentação detalhada sobre as características e análise dos resultados dos experimentos de lista ocorrerá adiante, quando descrevermos o experimento realizado sobre o PBF. No momento, serão feitas apenas considerações gerais sobre estudos que utilizaram essa técnica de pesquisa.

${ }^{4}$ Ou seja, do ponto de vista prático, "a presença de efeitos de desejabilidade social em pesquisas faz com que seja difícil estudar as fontes das opiniões acerca de tais questões, porque não se pode discernir com confiabilidade quem de fato possui qual opinião" (TURGEON; CHAVES; WIVES, 2014, p. 366).
} 
Dois exemplos são os artigos de Gilens (2001) e Turgeon e Rennó (2010). No primeiro, o grupo de tratamento recebeu informações sobre taxa de criminalidade e gastos do governo para ajudar outros países em dificuldade; e no segundo, sobre despesas e fontes de renda do Governo Federal e políticas públicas. Nas duas pesquisas, os resultados mostraram que a informação recebida foi suficiente para que as opiniões do grupo de tratamento fossem diferentes das do grupo controle. Ou seja, a informação a que se tem acesso importa.

\section{Descrição do experimento de lista}

Como mencionado, após o resultado da eleição de 2014, as redes sociais e aplicativos de troca de mensagens instantâneas foram inundados de manifestações preconceituosas sobre PBF e seus beneficiários. Por conta disso, surgiu a dúvida se o preconceito expresso sobre o programa era algo que ocorria apenas em círculos sociais mais íntimos, e que eventualmente alcançou o espaço público; se configurava um ato de revolta por conta do resultado da eleição, que poderia retroceder com informação ou "depois que a poeira baixasse"; ou se de fato externalizava um sentimento que até 2014 era mais latente do que manifesto.

A hipótese era que este último caso se aplicava, e essa ideia balizou a estratégia adotada para a construção do desenho de pesquisa. Assim, o primeiro passo era avaliar se o preconceito em relação ao PBF e seus beneficiários era latente e, em caso positivo, encontrar uma estimativa da sua dimensão. A partir da perspectiva de que os programas de transferência de renda são temas sensíveis, uma vez que essas políticas públicas são voltadas para as pessoas mais pobres, decidiu-se pela realização de um experimento de lista no questionário, cuja descrição segue abaixo.

A pesquisa de opinião pública nacional da Secom/PR, encomendada ao Ibope Inteligência e realizada entre os dias 22 e 28 de novembro de 2014, trouxe um bloco do questionário dedicado ao PBF. ${ }^{5}$ Nele perguntou-se diretamente aos entrevistados se eles seriam a favor ou contra o programa. A distribuição das respostas foi a seguinte: $62 \%$ a favor, $21 \%$ contra e $16 \%$ neutros. Mas essa frase não conseguia captar algo mais sutil, que é o preconceito ou até mesmo a incerteza, ou falta de

\footnotetext{
${ }^{5}$ Foram entrevistados 2002 brasileiros de 16 anos ou mais. Procedimento amostral: conglomerado em 3 estágios, sendo os dois primeiros sorteios probabilísticos dos municípios e dos setores censitários, e o terceiro por cotas de sexo, idade, escolaridade e ramo de atividade. Nível de confiança de $95 \%$ e erro de $\pm 2 \%$. Os relatórios das pesquisas estão disponíveis na página da Secom/PR.
} 
informação, que poderia levar as pessoas a rejeitarem o Bolsa Família (ALVAREz; BREHM, 1997). ${ }^{6}$

O experimento de lista foi desenhado justamente para lidar com essas questões. Seguiu-se formato semelhante ao utilizado nas pesquisas sobre gênero e raça citadas anteriormente. Para metade da amostra foi feita a seguinte pergunta:

Aqui estão algumas frases que falam sobre a pobreza no Brasil. Com quantas dessas frases o(a) sr(a) concorda em relação à pobreza no país? Não queremos saber com quais frases, mas sim com quantas delas o(a) sr(a) concorda. O(a) $\operatorname{sr}($ a) diria que concorda com 1, 2, 3 ou com nenhuma dessas frases.

1 - Nos últimos anos, o Brasil conseguiu diminuir a pobreza.

2 - Programas sociais ajudam a redistribuir melhor as riquezas do Brasil.

3-O governo brasileiro deve ser o principal responsável pelo bem-estar das pessoas.

Para a outra metade repetiu-se o enunciado, mas incluiu-se uma quarta frase, o "tratamento", referente ao programa PBF.

4- O programa Bolsa Família é uma forma errada de reduzir a pobreza.

Acreditamos que a frase utilizada no experimento é qualitativamente mais adequada para a tarefa de capturar o preconceito. Em 2014, uma crítica frequente sobre o programa era a de que ele era executado de forma incorreta, ainda que fosse necessário. Os recursos - "esmola" para os críticos - do PBF tornavam os beneficiários "preguiçosos" e dependentes do governo. Esse tipo de posicionamento também traz a ideia de que os favorecidos pelo programa seriam aproveitadores e pessoas de mau-caráter (CAMPello, 2013; MARQUeS; MAIA, 2012; RegO; PINZANI, 2013). O experimento permitia, portanto, dissociar a ideia de ser a favor do combate à pobreza do apoio ao PBF, já que descortinava uma percepção de que o programa não trataria dessa questão importante da forma "correta", desvirtuando-se do objetivo final de eliminar a pobreza e, no limite, servindo para outros fins.

Outro ponto importante é que não se perguntou com quais frases os respondentes concordavam, e sim com quantas delas, o que "elimina a preocupação do respondente sobre dar a resposta socialmente desejável e lhe permite responder mais honestamente" (STREB et al., 2008, p. 77). Isso significa que, ao se analisar os

\footnotetext{
${ }^{6}$ Gilens (1996, p. 593), por exemplo, sugeriu que políticas mais gerais de bem-estar social, como por exemplo as educacionais, de saúde e de benefício aos idosos, tendem a receber amplo apoio da opinião pública. As ambivalências e oposições surgem quando os benefícios são destinados aos pobres ou oferecem transferência direta de recursos em dinheiro ou transferências em espécie. Dentro desse contexto, autores como Skocpol (1990, 1991) defendem que políticas direcionadas a grupos específicos seriam menos eficientes do que as voltadas para ações mais gerais.
} 
dados, qualquer diferença encontrada nos valores médios das respostas entre os dois grupos somente pode ser atribuída à inclusão da quarta frase. A partir daí é possível estimar o percentual de entrevistados que de fato concordam com ela. Esse cálculo é feito com a subtração da média obtida pelo grupo de controle pela média do grupo de tratamento, multiplicada por $100 .^{7}$

Por fim, fez-se a seguinte pergunta para toda a amostra:

Agora eu gostaria que o(a) sr(a) me dissesse se concorda ou discorda com a seguinte afirmação: “O programa bolsa família é uma forma errada de reduzir a pobreza".

A seleção de quais entrevistados comporiam os grupos de controle e de tratamento foi feita de maneira aleatória na programação do questionário, cuja aplicação ocorreu por meio de tablets. ${ }^{8}$ Do total de entrevistados, 977 (48.8\% da amostra) compuseram o grupo de controle e 1025 (51.2\%) compuseram o grupo de tratamento. O perfil dos grupos era compatível. ${ }^{9} \mathrm{~A}$ seleção aleatória foi bemsucedida e permite-nos assumir que o grupo tratado teria se comportado como o grupo controle na ausência do tratamento. ${ }^{10}$ Testes de validação do experimento mostraram que não houve efeito de desenho, ou seja, que a adição de itens sensíveis não alterou as respostas aos itens de controle e que a resposta para cada item sensível é verdadeira. Dessa maneira, o método proposto permite-nos conduzir análises multivariadas com os resultados dos experimentos (BLAIR; IMAI, 2012; CORSTANGE, 2008; GLYNN, 2013; IMAI, 2011). ${ }^{11}$

\footnotetext{
${ }^{7}$ Por exemplo, se o valor médio das respostas do grupo tratamento for 2.17 e a do grupo controle for 1.91 , é possível estimar que $26.4 \%$ dos entrevistados $(2.17$ - $1.91=0.264 \times 100)$ concordam que o Bolsa Família é uma forma errada de reduzir a pobreza.

${ }^{8}$ Aqui vale uma observação importante. No desenho inicial do experimento, cada uma dessas perguntas era feita para $1 / 3$ da amostra. Mas por questões técnicas ligadas à programação dos questionários pelo Ibope Inteligência, optou-se por dividir a amostra em dois grupos: controle e tratamento. A pergunta aplicada para toda a mostra não contaminou o resultado do experimento.

${ }^{9}$ Testes de chi-quadrado não encontraram diferenças estatisticamente significativas entre ele em relação ao sexo (0.10, $p=0.75)$, idade $(8.54, p=0.20)$, grau de instrução $(10.6, p=0.31)$ e setor de atividade $(8.93, p=0.54)$. Testes de diferença de médias, não mostrados aqui, chegaram aos mesmos resultados.

${ }^{10}$ Ao comparar o resultado médio no grupo tratado com o resultado médio no grupo controle, o efeito médio do tratamento pode ser estimado. Por isso, a realização de testes estatísticos é fundamental para esclarecer se as diferenças entre os grupos ocorreram simplesmente por acaso (variabilidade da amostra) ou se são resultados do tratamento experimental (DRUCKMAN et al., 2011b).

${ }^{11}$ Os resultados dos testes podem ser solicitados ao primeiro autor do artigo pelo e-mail..
} 


\section{Os resultados do experimento de lista}

Quando perguntados diretamente pelo entrevistador se concordavam com a afirmação de que o PBF era uma forma errada de reduzir a pobreza, $47.05 \%$ disseram que concordavam, $47.45 \%$ que discordavam e $5.32 \%$ não souberam ou não responderam. ${ }^{12}$ Mas como os dados se comportam no experimento? A expectativa era encontrar uma diferença muito maior entre esses dois grupos, a favor da concordância com a frase. Como mostra a Tabela 1, não foi isso o que ocorreu.

Tabela 1 - percentual de pessoas que concordam que o PBF é uma forma errada de reduzir a pobreza

\begin{tabular}{lccc} 
& Tratamento & Controle & $\begin{array}{c}\text { Percentual } \\
\text { "concorda" }\end{array}$ \\
\hline Média & 2.14 & 1.92 & $22 \%$ \\
\hline Erro-padrão & $(0.032)$ & $(0.028)$ & $(0.043)^{*}$ \\
\hline $\mathrm{N}$ & 1025 & 977 & \\
\hline
\end{tabular}

Fonte: pesquisa quadrimestral Secom/PR - nov. $2014 .{ }^{*} p<.05$

Ao invés de um preconceito latente, o que se encontrou foi uma espécie de "apoio latente" ao PBF, pois apenas $22 \%$ dos entrevistados tenderiam a concordar com o fato de o programa ser uma forma errada de reduzir a pobreza. Ou seja, a partir do experimento, é possível estimar que em torno de $26 \%$ concordam com a afirmação, e que $69 \%$ discordam da mesma. Esse resultado é surpreendente e vai no sentido contrário à grande parte dos estudos sobre temas sensíveis, que geralmente mostram como as pessoas escondem opiniões que poderiam ser consideradas politicamente incorretas.

Uma explicação para esse comportamento encontra-se na teoria do espiral do silêncio. Tal explicação pressupõe que as pessoas avaliam o seu ambiente para captar o clima de opinião e que, por conta do medo de isolamento social, omitem suas visões e preferências quando estas são conflitantes com o que acreditam ser a opinião dominante (NOELLE-NEUMANN, 1993; SCHEUFELE; MoY, 2000).

Mas, em novembro de 2014, qual era a opinião dominante sobre o PBF? Uma das dificuldades de se responder a essa pergunta é que não dispomos de dados para afirmar quais seriam as principais fontes de informação das pessoas em relação ao programa. A melhor descrição disponível encontra-se na rodada de

\footnotetext{
${ }^{12}$ As frequências dessas respostas, apenas para o grupo de controle, são de $47.8 \%$ para os que concordam, $46.9 \%$ para os que discordam e $5.32 \%$ não souberam ou não quiseram responder.
} 
pesquisa qualitativa, de novembro de 2014, da Secom/PR ("Estudo Qualitativo Ad hoc - Conjuntura Brasileira III (11/2014)", 2014). ${ }^{13}$ Nela, perguntou-se aos participantes de 24 grupos focais onde se informavam sobre o PBF. Segundo o relatório da pesquisa, as fontes primárias de informação seriam amigos, familiares ou os próprios beneficiários do programa. As fontes secundárias, reconhecidas como escassas e superficiais, seriam a imprensa tradicional, as redes sociais e as informações veiculadas durante a campanha presidencial. Além disso, pelos relatos colhidos, observa-se que algumas fontes de informação a que o grande público recorre contribuem para aumentar alguns vieses acerca do programa. Em parte delas, principalmente nas redes sociais, parecem correr informações errôneas, preconceituosas ou distorcidas sobre a mecânica e o funcionamento do Bolsa Família ("Estudo Qualitativo Ad hoc - Conjuntura Brasileira III (11/2014)", 2014, p. 34).

Embora esses dados não permitam inferências populacionais, eles nos ajudam a traçar um possível cenário informacional do período em que o experimento foi realizado. As informações oriundas de reportagens da imprensa sobre o PBF que, segundo estudos, tendem historicamente para um viés negativo (BIROLI; MANTOVANI, 2010; MARQUES, 2010), ajudariam a compor o modelo clássico da formação de um clima de opinião dominante a partir dos meios de comunicação tradicionais. Já as falas contra o programa e seus beneficiários que circularam de modo contundente nas novas mídias, enfatizariam os impactos do que Moy et al. (2001) chamaram de "micro climas de opinião", mediados pelas redes sociais e aplicativos de troca de mensagens instantâneas.

Se os entrevistados levaram em conta algum tipo de análise do clima de opinião para responderem às perguntas sobre o PBF nas pesquisas, provavelmente foram influenciados por uma percepção de que o programa era mais rejeitado do que aceito pela maioria dos brasileiros, ou de que as críticas ao seu funcionamento e beneficiários eram maiores que seus benefícios, reforçando a imagem de que ele poderia ser uma forma errada de combater a pobreza. Se, por um lado, isso pode ter levado muitos respondentes a omitirem uma visão mais positiva, por outro mostra como os brasileiros ainda são sensíveis ao combate à pobreza e à desigualdade social.

Mas quem concorda com o item sensível?

O problema do simples teste de diferença entre médias é que ele não permite analisar quais características dos entrevistados impactam a probabilidade de se concordar com o item sensível do experimento. A estimação de um modelo de

\footnotetext{
${ }^{13} \mathrm{O}$ relatório da pesquisa encontra-se disponível na página da Secom/PR.
} 
regressão multivariada da técnica de contagem de itens criada por Imai (2011) e Blair e Imai (2012) permite-nos identificá-las.

Para essa análise, trabalhou-se com quatro grupo de variáveis. O primeiro deles contempla as características sociodemográficas: cor branca, homem, idade, escolaridade e renda familiar mensal. ${ }^{14} \mathrm{O}$ segundo grupo contempla as variáveis midiáticas, que captam o meio de comunicação que os entrevistados mais usam para se informar. A pergunta oferecia até duas opções de reposta, mas consideramos apenas a primeira. Foram criadas duas variáveis: quem utiliza mais o Jornal Nacional e quem se informa em portais de notícia ou redes sociais.

O terceiro grupo contempla as variáveis políticas: avaliação do Governo Federal, numa escala que vai de péssimo a ótimo, e um índice que buscou captar o individualismo do entrevistado (FELDMAN, 1982; FELDMAN; ZaLLER, 1992). Neste caso, a pesquisa trouxe três perguntas em que ele devia escolher, entre duas frases, com qual concordava mais. As frases contrapunham uma visão liberal com uma visão a favor de maior presença do Estado na vida das pessoas. ${ }^{15}$ Para cada uma das perguntas foi criada uma nova variável, sendo 1 para as respostas liberais e 0 para as demais, incluindo não sabe e não respondeu. Todos os valores foram somados, constituindo-se uma nova variável, com valor mínimo de zero, máximo de três, média de 1.46, desvio-padrão de 0.99 e um alfa de Cronbach de 0.373. ${ }^{16}$

O último grupo de variáveis é ligado ao PBF. Foram criados três índices a partir de frases associadas ao programa, derivados de uma bateria de dez perguntas em que os entrevistados poderiam dizer que discordavam da frase, assumir uma posição neutra ou concordar com o que foi lido pelo entrevistador. ${ }^{17} \mathrm{O}$ primeiro mediu os "impactos sociais" do PBF sobre seus beneficiários e o país. Quanto maior o valor, maior o nível de concordância do entrevistado com visões positivas sobre PBF. O segundo mediu o nível de "preconceito" em relação ao PBF e beneficiários. Quanto maior o valor, mais o entrevistado apresentava visões negativas. O terceiro mediu a crítica à suposta falta de "controle" do programa. Quanto maior o valor,

\footnotetext{
${ }^{14}$ A configuração das variáveis foi a seguinte. Grupo de idade: 16 a 24 anos, 25 a 34, 35 a 44, 45 a 54 e acima de 55;

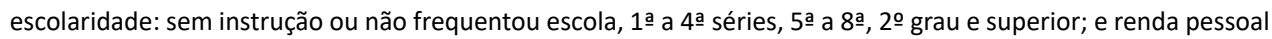
mensal: até 1 salário mínimo, 1 a 2, 2 a 5 e acima de 5 .

${ }^{15}$ As frases são: "Boa parte da pobreza está ligada à preguiça de pessoas que não querem trabalhar" versus "Boa parte da pobreza está ligada à falta de oportunidades iguais para que todos possam subir na vida"; "Quanto menos eu depender do governo, melhor estará minha vida" versus "quanto mais benefícios do governo eu tiver, melhor estará minha vida"; e "As pessoas precisam da ajuda do governo para melhorar de vida" versus "As pessoas são capazes de melhorar de vida por si próprias, e a ajuda do governo acaba as deixando acomodadas".

${ }^{16}$ Sabemos que esse índice está longe da perfeição. Por isso, suas análises devem ser vistas com a devida cautela.

${ }^{17}$ As frases, suas respectivas distribuições e as indicações sobre os índices que cada uma delas compõem podem ser solicitados ao primeiro autor do artigo pelo e-mail..
} 
mais o entrevistado acreditava que o PBF repassava recursos para pessoas que não mereciam. As estatísticas descritivas estão na Tabela 2.

Tabela 2 - Estatísticas descritivas dos índices

\begin{tabular}{lcccccc} 
Índice & Média & $\begin{array}{c}\text { Desv. } \\
\text { pad. }\end{array}$ & Min. & Max. & Alfa & N \\
Impactos sociais & 11.73 & 3.24 & 5 & 15 & 0.817 & 1872 \\
\hline Preconceitos & 6.92 & 2.04 & 3 & 9 & 0.674 & 1881 \\
Controles & 5.12 & 1.31 & 2 & 6 & 0.659 & 1905
\end{tabular}

Fonte: Pesquisa quadrimestral de opinião pública Secom/PR - nov. 2014

Foram incluídas, também: variáveis binárias derivadas da pergunta que busca levantar se o entrevistado, ou alguém que mora com ele, é beneficiário de algum programa do Governo Federal; e um índice de conhecimento sobre o PBF, formado a partir de uma bateria de quatro perguntas, para medir o nível de conhecimento do entrevistado sobre o programa. Para cada uma delas foi criada uma nova variável, sendo 1 para as respostas certas e 0 para as respostas erradas, não sabe e não respondeu. Todos os valores foram somados, constituindo-se uma nova variável com valor mínimo de zero, máximo de quatro, média de 1.954, desvio-padrão de 1.067 e um alfa de Cronbach de 0.382 .

Como a pergunta do experimento pedia para indicar com quantos itens se concordava, coeficientes com sinais positivos mostram maior probabilidade de se concordar com o item sensível, ou seja, concordar que o PBF é uma forma errada de se reduzir a pobreza; sinais negativos assinalam uma diminuição na probabilidade de se concordar com essa afirmação. Foram estimados dois modelos, sendo que apenas o segundo incluiu as medidas derivadas dos índices de impactos sociais, preconceitos e controles. A Tabela 3 traz os resultados.

Tabela 3 - Coeficientes estimados dos modelos de regressão da técnica de contagem de itens

\section{Modelo 1}

Est.

$$
\text { Intercepto }
$$

$0.904 * *$

$-0.073$

$-0.029$

Avaliação do Governo

Federal

Homem
E.P.

0.347

0.047

0.095

0.095

\section{Modelo 2}

Est. E.P.

$1.15^{* *} \quad 0.427$

$\begin{array}{ll}-0.021 & 0.048\end{array}$

$\begin{array}{ll}-0.055 & 0.097\end{array}$




\begin{tabular}{lllll}
\hline Escolaridade & -0.058 & 0.052 & -0.065 & 0.052 \\
\hline Idade & $-0.074 *$ & 0.034 & $-0.068^{*}$ & 0.035 \\
\hline Renda familiar mensal & 0.000 & 0.056 & -0.009 & 0.057 \\
\hline Branca & -0.012 & 0.101 & -0.054 & 0.104 \\
\hline Nordeste & -0.040 & 0.143 & 0.014 & 0.153 \\
\hline Sudeste & 0.000 & 0.139 & -0.095 & 0.146 \\
\hline Sul & 0.244 & 0.178 & 0.280 & 0.186 \\
\hline Jornal Nacional & -0.064 & 0.099 & -0.119 & 0.103 \\
\hline Internet & -0.075 & 0.175 & -0.127 & 0.178 \\
\hline $\begin{array}{l}\text { Conhecimento sobre } \\
\text { BF }\end{array}$ & -0.071 & 0.044 & $-0.079 *$ & 0.046 \\
\hline Beneficiário do PBF & -0.116 & 0.162 & -0.083 & 0.166 \\
\hline $\begin{array}{l}\text { Conhece beneficiário } \\
\text { do PBF }\end{array}$ & -0.122 & 0.128 & -0.155 & 0.132 \\
\hline $\begin{array}{l}\text { Individualismo } \\
\text { Impactos sociais }\end{array}$ & $0.107^{* *}$ & 0.047 & 0.057 & 0.051 \\
\hline $\begin{array}{l}\text { Preconceitos } \\
\text { Controle }\end{array}$ & - & - & $-0.075^{* *}$ & 0.018 \\
\hline
\end{tabular}

Fonte: pesquisa quadrimestral Secom/PR - nov. $2014{ }^{* *} p<.05,^{*} p<.10$

Poucas variáveis incluídas nos modelos alcançaram significância estatística. São os entrevistados mais jovens os que apresentaram maior probabilidade de aceitar que o PBF é uma forma errada de combater a pobreza, já que, à medida em que aumenta a idade do entrevistado, menores são as chances de concordar com o item sensível. E, conforme esperado, são os adeptos do individualismo - que defendem visões como "boa parte da pobreza está ligada à preguiça de pessoas que não querem trabalhar", "quanto menos eu depender do governo, melhor estará minha vida" e "as pessoas são capazes de melhorar de vida por si próprias, e a ajuda do governo acaba as deixando acomodadas" - os que mais estariam inclinados a apoiar a ideia de que o PBF é uma forma errada de combater a pobreza.

Embora a inclusão dos índices vinculados às impressões sobre o PBF tenha suprimido os efeitos do individualismo no modelo 2 , ressalta-se a coerência das relações entre essas variáveis e o item sensível. Apenas para deixar claras as relações encontradas, a probabilidade de se concordar com o item sensível é maior entre 
aqueles que tendem a concordar que o programa "favorece a acomodação dos beneficiários", "incentiva as pessoas a terem mais filhos para receber o benefício" ou "há pouco controle sobre quem deve de fato receber o programa", e é menor entre aqueles que tendem a concordar que o PBF "melhorou a vida das pessoas pobres no Brasil" ou "ajudou a reduzir a desigualdade no Brasil".

Essa interpretação sugere que a opinião do programa ser, ou não, uma forma errada de reduzir a pobreza está ligada mais a componentes ideológicos, no caso dos índices de impactos e preconceitos, e de percepção, no caso dos índices de impactos sociais e controle, do que contextuais, ou seja, apoiar ou não um determinado governo ou morar numa determinada região do país, por exemplo. Acreditamos que isso reforça, por um lado, a impressão de que o resultado da eleição de 2014 serviu como um estopim para que visões preconceituosas ou mitos (CAMPello, 2013; Rego; PINZANI, 2013) sobre o PBF emergissem ou fossem reforçadas no espaço público; e, por outro, que a agressividade com que essas falas foram expostas fez com que muitas pessoas com uma visão mais positiva do PBF escondessem sua verdadeira opinião.

\section{A descrição dos experimentos de informação}

Os experimentos de informação foram executados em duas rodadas de pesquisa telefônica nacional, realizadas entre os dias 5 e 11 de junho, e 26 de junho e 1은 de julho, ambas em 2015. ${ }^{18} \mathrm{O}$ enunciado das perguntas da primeira pesquisa pode ser visto abaixo. Para que as condições entre os grupos fossem as mais próximas possíveis, ambos foram questionados sobre notícias a respeito do PBF e beneficiários. Mas apenas o grupo de tratamento recebeu a "informação relevante" passada pelo entrevistador, assinalada em negrito (GILENS, 2001). É irrelevante se o entrevistado mentiu ao dizer que ficou ou não sabendo da notícia. O importante era avaliar se a informação recebida fez diferença.

Agora gostaria de falar com o(a) sr(a) sobre algumas notícias divulgadas pela imprensa nos últimos dias.

A primeira delas é sobre o número de filhos das famílias que recebem o benefício do Bolsa Família. Segundo a notícia, as famílias que recebem o benefício do Bolsa Família tiveram menos filhos que a média brasileira entre os anos de 2003 e 2013. O(A) sr(a) ficou sabendo dessa notícia?

\footnotetext{
${ }^{18}$ Ambas entrevistaram 1000 brasileiros de 16 anos ou mais, com acesso a telefone fixo (51\%) e celular (49\%). Procedimento amostral: método PPT no primeiro estágio através dos números de telefone e por cotas de sexo, idade, grau de escolaridade e ramo de atividade no segundo estágio. Nível de confiança de $95 \%$ e erro de $\pm 3 \%$. Os relatórios das pesquisas estão disponíveis na página da Secom/PR.
} 
A segunda notícia é sobre o mapa mundial da fome da ONU. Nos últimos dez anos o Brasil reduziu pela metade a parcela da população que sofre com a fome e conseguiu sair do mapa da fome da ONU em 2014. $O(A) \operatorname{sr}(a)$ ficou sabendo dessa notícia?

A terceira notícia é sobre a extrema pobreza no Brasil. De 2001 e 2013, o percentual da população brasileira vivendo em extrema pobreza caiu de $10 \%$ para $4 \%$. $O(A)$ sr(a) ficou sabendo dessa notícia?

A última notícia é sobre o número de famílias que deixaram de participar do programa Bolsa Família. Desde 2003 mais de três milhões de famílias deixaram de receber a ajuda do Bolsa Família porque aumentaram a renda e melhoraram de vida. $O(A) \operatorname{sr}(a)$ ficou sabendo dessa notícia?

O enunciado das perguntas da pesquisa telefônica realizada entre 26 de junho e 1 o de julho pode ser visto abaixo.

Agora gostaria de falar com o(a) sr(a) sobre algumas notícias divulgadas pela imprensa nos últimos dias.

A primeira delas é sobre o número de filhos das famílias que recebem o benefício do Bolsa Família. Segundo a notícia, as famílias que recebem o benefício do Bolsa Família tiveram menos filhos que a média brasileira entre os anos de 2003 e 2013. O(A) sr(a) ficou sabendo dessa notícia?

A segunda notícia é sobre a redução da mortalidade infantil. O Bolsa Família conseguiu diminuir em $46 \%$ a mortalidade infantil causada por diarreia, e em $\mathbf{5 8 \%}$ a mortalidade infantil causada por desnutrição. $O(A)$ sr(a) ficou sabendo dessa notícia?

A última notícia é sobre evasão escolar. 0 Bolsa Família reduz a evasão escolar em 36\%, entre crianças de 6 a 16 anos. $O(A)$ sr(a) ficou sabendo dessa notícia?

A seleção de quais entrevistados comporiam os grupos de controle e tratamento foi feita de maneira aleatória na aplicação do questionário. Do total de entrevistados, respectivamente 498 (49.8\% da amostra) e 499 (49.9\% da amostra) compuseram os grupos de controle das pesquisas, e 502 (50.2\%) e 501 (50.15) compuseram os grupos de tratamento. 0 perfil dos grupos era compatível. ${ }^{19}$

\section{Os resultados dos experimentos de informação}

Seguimos o mesmo procedimento adotado por Gilens (2001) e Turgeon e Rennó (2010) e estimamos 12 modelos logísticos para determinar o efeito do repasse de

\footnotetext{
${ }^{19}$ Testes de chi-quadrado não encontraram diferenças estatisticamente significativas (valores médios) entre os dois grupos em relação ao sexo $(0.39, p=0.64)$, idade $(3.70, p=0.72)$, grau de instrução $(1.09, p=0.78)$ e setor de atividade $(1.77, p=0.43)$. Testes de diferença de médias, não mostrados aqui, chegaram aos mesmos resultados.
} 
informações sobre o PBF na opinião dos entrevistados. As variáveis dependentes foram codificadas da seguinte forma: atribuímos o valor de um para as avaliações positivas (ótima e boa) do PBF, e zero para as demais respostas; e o valor de um para opiniões favoráveis ao programa, e zero para as demais respostas. ${ }^{20}$

Nas pesquisas telefônicas foi incluída uma pergunta para apreender qual frase melhor descreveria o pensamento dos entrevistados sobre o PBF. As opções eram: é um direito das pessoas que precisam de ajuda; é um programa que gera comodismo; é um programa que reduz a pobreza das gerações futuras; e é um programa meramente assistencialista. Cada uma das frases foi transformada em uma variável binária, sendo um para a respectiva resposta, e zero para as demais.

As variáveis de controle foram a avaliação do governo, ser beneficiário do PBF, conhecer um beneficiário, ser homem, escolaridade, idade dos entrevistados, renda familiar mensal e região do país onde se mora. ${ }^{21}$ Infelizmente, os questionários das pesquisas telefônicas da Secom/PR não incluem a pergunta sobre a autodeclaração de cor do entrevistado. Para os modelos estimados com a pesquisa dos dias 5 a 11 de julho também foi incluída a opinião dos entrevistados sobre se a vida das pessoas pobres no Brasil havia piorado, ficado igual ou melhorado nos últimos 12 meses.

Dos 12 modelos estimados, apenas um encontrou efeitos do tratamento na opinião dos entrevistados. As informações repassadas na pesquisa dos dias 26 de junho a 1 o de julho diminuíram a probabilidade de dizer que o PBF gera comodismo $(B=-.39, p<.05)$, ceteris paribus. Por conta disso, estimamos uma nova regressão logística para calcular o efeito médio do tratamento, mas agora tendo como variáveis de controle apenas aquelas que alcançaram significância estatística (WILLIAMS, 2012). A Tabela 4 traz os resultados dessas estimativas.

Tabela 4 - Estimação da probabilidade de dizer que o PBF gera comodismo

\begin{tabular}{lcccc} 
& Tratamento & Controle & Diferença & chi2 \\
\hline Geral & 0.318 & 0.393 & -0.074 & $4.85^{* *}$ \\
\hline Sexo & & & & \\
\hline Homem & 0.278 & 0.349 & -0.071 & $4.87^{* *}$ \\
\hline
\end{tabular}

\footnotetext{
${ }^{20}$ Aqui optamos por uma configuração mais simples das variáveis dependentes. Outras formatações não alteraram os resultados das análises.

${ }^{21}$ A configuração das variáveis foi a seguinte. Avaliação do Governo Federal: péssimo, ruim, regular, bom e ótimo; grupo de idade: 16 a 24 anos, 25 a 34, 35 a 44, 45 a 54 e acima de 55; escolaridade: até 4a série, 5a a 8a , 20 grau e superior; Porte do município: até 20 mil habitantes, 20 a 50, 50 a 100, 100 a 500 e acima de 500 mil; e região do país: SE, NE, Sul e NO/CO (referência).
} 
Mulher

0.356

0.433

$-0.077$

$4.81^{* *}$

Renda familiar

\begin{tabular}{lllll} 
Até 1 SM & 0.162 & 0.214 & -0.052 & $4.65^{* *}$ \\
\hline 1 a 2 SM & 0.334 & 0.411 & -0.077 & $4.81^{* *}$ \\
\hline 2 a 5 SM & 0.382 & 0.464 & -0.081 & $4.83^{* *}$ \\
\hline Acima de 5 SM & 0.324 & 0.400 & -0.077 & $4.75^{* *}$
\end{tabular}

Avaliação do Governo

Federal

\begin{tabular}{lllll}
\hline Ruim/Péssimo & 0.352 & 0.430 & -0.078 & $4.86^{* *}$ \\
\hline Regular & 0.261 & 0.331 & -0.070 & $4.80^{* *}$ \\
\hline Ótimo/Bom & 0.143 & 0.191 & -0.047 & $3.62^{*}$
\end{tabular}

Beneficiário do PBF

\begin{tabular}{lllll}
\hline Não & 0.332 & 0.408 & -0.076 & $4.87^{* *}$ \\
\hline Sim & 0.215 & 0.275 & -0.060 & $4.48^{* *}$ \\
\hline Idade & & & & \\
\hline 16 a 24 anos & 0.260 & 0.329 & -0.068 & $4.84^{* *}$ \\
\hline 25 a 34 anos & 0.256 & 0.326 & -0.069 & $4.75^{* *}$ \\
\hline 35 a 44 anos & 0.314 & 0.389 & -0.075 & $4.76^{* *}$ \\
\hline 45 a 54 anos & 0.406 & 0.486 & -0.080 & $4.83^{* *}$ \\
\hline Acima de 55 anos & 0.366 & 0.445 & -0.079 & $4.84^{* *}$
\end{tabular}

Fonte: pesquisa telefônica Secom/PR -1 ㅇ jul. 2015, ${ }^{* *} p<.05 * p<.10$

Como mostram os efeitos médios estimados, se todos os entrevistados tivessem recebido as informações, a probabilidade de dizer que o PBF gera comodismo seria de $31.8 \%$, contra $39.3 \%$, se nenhum dos entrevistados as tivesse recebido. Assim, receber informações sobre o PBF diminuiu em $7.4 \%$ a probabilidade de os entrevistados dizerem que o programa gera comodismo.

Os dados também sugerem que os efeitos do tratamento foram maiores, em especial, entre críticos do Governo Federal. Se todos os entrevistados que os avaliavam negativamente tivessem recebido as informações sobre o PBF, a probabilidade de dizer que o programa gera comodismo seria $7.8 \%$ menor, contra $4.7 \%$, se os entrevistados o considerassem como bom/ótimo. Na época, isso era uma boa notícia, já que simplesmente "pregar para os convertidos" faria pouca diferença para alterar as visões mais negativas. 
No geral, pode-se dizer que as informações repassadas não conseguiram mudar a opinião das pessoas. Ao menos três explicações podem ser dadas. Em primeiro lugar, tais efeitos seriam realmente baixos, pois as medidas de avaliação sobre o programa ainda teriam o efeito de desejabilidade social. As visões dos entrevistados sobre o PBF seriam mais positivas do que as pesquisas conseguiriam captar. Mas os objetivos dos experimentos informacionais buscavam justamente diminuir a rejeição ao programa. Uma saída para essa questão teria sido aplicar, na mesma pesquisa, um experimento de lista e um experimento de informação (BLAIR; IMAI; LYALL, 2014).

Em segundo lugar, como mostrou Zaller (1992), a maneira como a atenção política está distribuída na sociedade interfere na maneira como se lida com as informações recebidas. Pessoas com atenção política mais alta acessam uma gama maior de crenças, atitudes relevantes e experiências anteriores; pensam de maneira mais especializada e processam informações no domínio relevante; e usam uma maior reserva de informação e experiências para interpretar e avaliar novas informações sobre um tema. Já pessoas com atenção política mais baixa têm dificuldade em perceber, compreender e avaliar as informações relevantes. Podem errar, interpretar incorretamente ou avaliar mal pontos importantes de um determinado tema (WOOD, WENDY; RHODES; BIEK, 1995).

Portanto, os baixos efeitos da informação no experimento poderiam ser explicados pelo baixo nível de atenção política. As pessoas com maior atenção política têm atitudes e opiniões fortemente cristalizadas e dificilmente mudariam de opinião devido ao ganho de informação. Mas elas são minoritárias. Já as pessoas com atenção política baixa tenderiam a internalizar um número menor de considerações, possuir menos motivação para perceber, entender e reconhecer os méritos de novas informações (WOOD, WENDY; RHODES; BIEK, 1995; ZALLER, 1992). Assim, mais informação em nosso contexto experimental não apresenta efeitos porque não há uma estrutura de conhecimento bem organizada que proporcione uma base informativa prévia para avaliar a informação de interesse.

Por fim, as pesquisas da Secom/PR mostraram que o PBF sempre era uma das ações ou políticas do Governo Federal mais lembradas pelos brasileiros. Embora o nível de informação sobre o programa fosse baixo, é possível que as opiniões das pessoas sobre o PBF estivessem cristalizadas, o que dificultaria qualquer mudança. Dado o contexto, as discussões políticas que polarizaram o país durante a eleição podem ter gerado uma espécie de externalidade negativa: o reforço de determinadas visões de mundo, ainda que baseadas em dados incorretos. Do ponto de vista político, a consequência prática é que, mesmo à luz de novas e verdadeiras informações, existe a possibilidade de que as pessoas tendam a se agarrar às 
suas convicções, e inclusive duvidar da veracidade dessas novas informações, dificultando qualquer tipo de persuasão ou mudança de opinião (DRUCKMAN; Peterson; Slothuus, 2013; Nyhan; ReifLer, 2010).

\section{Conclusões}

Embora seja o Programa Bolsa Família uma importante política de combate à pobreza, com resultados efetivos, as análises apresentadas neste artigo mostraram que a opinião pública em relação a ele é complexa. Se questionados de modo direto, $47.05 \%$ dos brasileiros concordam que o programa é uma forma errada de combater a pobreza. Mas como mostram os resultados do experimento de lista, esse número é efetivamente menor: $22 \%$. Ou seja, ao menos em novembro de 2014 , houve a tendência de uma parcela da opinião pública em esconder um posicionamento mais favorável ao PBF.

É possível que uma percepção, ainda que equivocada, sobre o clima de opinião dominante e formado pós-eleição de 2014, com críticas intensas e raivosas contra o PBF e seus beneficiários, tenha levado muitos respondentes a omitirem uma visão mais favorável ao programa. $O$ ponto positivo é que isso mostra como os brasileiros ainda são sensíveis ao combate à pobreza e à desigualdade social.

As análises deste artigo também ajudam a pensar a comunicação governamental. O uso de experimentos de informação poderia ser uma prática mais difundida. Eles permitem avaliar, de maneira mais substantiva, a eficácia de determinadas estratégias de disseminação de informação. Isso ajudaria a economizar recursos públicos, pois tornariam desnecessários gastos com campanhas que trouxessem mensagens pouco eficientes.

Ao mesmo tempo, é possível que as dificuldades encontradas na persuasão dos entrevistados sobre o PBF se apliquem a outras políticas públicas. Nesses casos, as campanhas devem ter objetivos diferentes da simples persuasão de corações e mentes. No caso do PBF, com base nos experimentos discutidos, parece ser mais eficiente uma comunicação voltada para constranger publicamente falas preconceituosas ou equivocadas dos interlocutores mais críticos do que a busca por uma mudança de opinião.

Como qualquer técnica, os experimentos descritos neste artigo têm limitações e não são infalíveis (KINDER; PALFREY, 1993b). Acreditamos na consistência dos dados apresentados e nos desenhos das pesquisas utilizadas, mas ressaltamos a necessidade de novos estudos para dirimir as dúvidas e contradições apresentadas neste artigo. Talvez o seu maior mérito seja a tentativa de se analisar um tema bastante complexo e pouquíssimo estudado, que é a opinião pública brasileira sobre o PBF. Do ponto de 
vista político, isso ainda é importante. Para além do seu impacto social, o programa mostrou ter efeitos eleitorais substantivos e, por isso, continuará sendo um tema de disputa entre as forças que se digladiam pelo poder no país.

\section{Referências bibliográficas}

Althaus, Scott L. Information effects in collective preferences. American Political Science Review, v. 92, n. 3, p. 545-558, 1998.

Alvarez, R. Michael; Brehm, John. Are Americans ambivalent towards racial policies? American Jounal of Political Science, v. 41, n. 2, p. 345-374, 1997.

ANSOLABEHERE, Stephen; IYENGAR, Shanto. Going negative: how political advertisements shrink and polarize the electorate. [S.I.]: The Free Press, 1995.

AzeVedo, Fernando Antônio. Agendamento da política. In: RUBIM, Antonio Albino Canelas (org.).. Comunicação política: conceitos e abordagens. Salvador, São Paulo: Editora UFBA, Editora Unesp, 2004. p. 41-72.

BARTELS, Larry M. Uninfored votes: information effects in president elections. American Journal of Political Science, v. 40, n. 1, p. 194-230, fev. 1996.

BERINSKY, Adam J. Silent voices: social welfare policy opinions and political equality in America. American Jounal of Political Science, v. 46, n. 2, p. 276-287, 2002.

BERINSKY, Adam J. The two faces of public opinion. American Journal of Political Science, v. 43, n. 4, p. 1209-1230, 1999.

BIROLI, Flávia; MANTOVANI, Denise. Disputas, ajustes e acomodações na produção da agenda eleitoral: a cobertura jornalística ao Programa Bolsa Família e as eleições de 2006. Opinião Pública, v. 16, n. 1, p. 90-116, 2010.

BLAIR, Graeme; IMAI, Kosuke. Statistical analysis of list experiments. Political Analysis, v. 20, p. 47-77, 2012.

BLAIR, Graeme; IMAI, Kosuke; LYALL, Jason. Comparing and combining list and endorsement experiments: evidence from Afghanistan. American Journal of Political Science, v. 58, n. 4, p. 1043-1106, 2014.

CAMPBELL, Angus et al. The American voter: an abridgment. New York: John Wiley \& Sons, 1967.

CAMPELlo, Tereza. Uma década derrubando mitos e superando expectativas. In: CAMPello, Tereza; Nerı, Marcelo Côrtes (org.). Programa Bolsa Família: uma década de inclusão e cidadania. Brasília: Ipea 2013. p. 15-24.

CORSTANGE, Daniel. Sensitive questions, truthful answers? Modeling the list experiment with Listit. Political Analysis, v. 17, n. 1, p. 45-63, 2008.

DRUCKMAN, James N. et al. Cambridge handbook of experimental Political Science. In: DruckMAN, James N. et al. (org.). [S.I.]: Cambridge University Press, 2011a. p. 3-14.

DRUCKMAN, James N. et al. Experiments: an introduction to core concepts. In: DRUCKMAN, James N. et al. (org.). Cambridge handbook of experimental Political Science. [S.I.]: Cambridge University Press, 2011b. p. 15-26. 
DRUCKMAN, James N. et al. The growth and development of experimental research in Political Science. American Political Science Review, v. 100, n. 4, p. 627-635, 2006.

Druckman, James N.; Peterson, Erik; SlothuUs, Rune. How elite partisan polarization affects public opinion formation. American Political Science Review, v. 107, n. 1, p. 57-79, 2013.

Estudo Qualitativo Ad hoc - Conjuntura Brasileira III (11/2014). Brasília: Assessoria de Pesquisa de Opinião Pública - Secretaria de Comunicação Social da Presidência da República, 17 dez. 2014.

FELDMAN, Stanley. Economic self-interest and political behavior. American Jounal of Political Science, v. 26, n. 3, p. 446-466, 1982.

FELDMAN, Stanley; ZALLER, John R. The political culture of ambivalence: ideological responses to the welfare State. American Jounal of Political Science, v. 36, n. 1, p. 268-307, 1992.

Gerber, Alan S. Field experiments in Political Science. In: DrUCKMAN, James N. et al. (org.). Cambridge handbook of experimental Political Science. [S.I.]: Cambridge University Press, 2011. p. 115-140.

Gerber, Alan S.; KARLAN, Dear; Bergan, Daniel. Does the media matter? A field experiment measuring the effect of newspapers on voting behavior and political opinions. American Economic Journal: applied Economics, v. 1, n. 2, p. 35-52, 2009. GILENS, Martin. Political ignorance and collective policy preferences. American Political Science Review, v. 95, n. 2, p. 379-396, 2001.

GILENS, Martin. "Race Coding" and white opposition to welfare. American Political Science Review, v. 90, n. 3, p. 593-604, 1996.

GLYNN, Adan N. What can we learn with statistical truth serum?: Design and analysis of the list experiment. Public Opinion Quarterly, v. 77, n. 1, p. 159-172, 2013.

HASENFELD, Yeheskel; RAFFERTY, Jane A. The determinants of public attitudes toward the welfare State. Social Forces, v. 67, n. 4, p. 1027-1048, 1989.

HolLAND, Paul W. Statistics and causal inference. Journal of the American Statistical Association, v. 81, n. 396, p. 945-960, 1986.

IMAI, Kosuke. Multivariate regression analysis for the item count technique. Journal of the American Statistical Association, v. 106, n. 494, p. 407-416, 2011.

IYENGAR, Shanto. Laboratory experiments in Political Science. In: DRUCKMAN, James N. et al. (org.). Cambridge handbook of experimental Political Science. [S.I.]: Cambridge University Press, 2011. p. 73-88.

IYENGAR, Shanto; KINDER, And Donald. News that matter: television and American opinion. Chicago and London: the University of Chicago Press, 1987.

JANUS, Alexander L. The influence of social desirability pressures on expressed immigration attitudes. Social Science Quarterly, v. 91, n. 4, p. 928-946, 2010.

KANE, James G.; CrAIG, Stephen C.; WALD, Kenneth D. Religion and presidential politics in Florida: a list experiment. Social Science Quarterly, v. 85, n. 2, p. 281-293, 2004. 
KINDER, Donald R. Campbell's Ghost. In: DrUCKMAN, James N. et al. (org.). Cambridge handbook of experimental Political Science. New York: Cambridge University Press, 2011. p. 525-529.

KINDER, Donald R.; PALfReY, Thomas R. (org.). Experimental foundations of Political Science. Ann Arbor: the University of Michigan Press, 1993a.

KINDER, Donald R.; PALFREY, Thomas R. On behalf of an experimental political science. In: KINDER, Donald R.; PALFREY, Thomas R. (org.). Experimental foundations of political science. Ann Arbor: the University of Michigan Press, 1993b. p. 1-39.

KING, Gary; KeOHANE, Robert O.; VerBA, Sidney. Designing social inquiry: scientific inference in qualitative research. Princeton: Princeton University Press, 1994.

KUKLINSKI, James $\mathrm{H}$. et al. Racial prejudice and attitudes toward affirmative action. American Jounal of Political Science, v. 41, n. 2, p. 402-419, 1997.

KUKLINSKI, James H.; COBB, Michael D.; GILENS, Martin. Racial attitudes and the "New South". The Journal of Politics, v. 59, n. 2, p. 323-349, 1997.

LAZARSFeld, Paul F.; Berelson, Bernard; Gaudet, Hazel. The people's choice: how the voter makes up his mind in a presidential election. 6. ed. New York: Columbia University Press, 1948.

LUPIA, Arthur. Shortcuts versus encyclopedias: information and voting behaivior in California insurance reform elections. American Political Science Review, v. 88, n. 1, p. 63-76, mar. 1994.

LUPIA, Arthur; MccuBbINS, Matthew D. The institutional foundations of political competence: how citzens learn what they need to know. In: LUPIA, Arthur; McCUBBINS, Matthew D.; POPKIN, Samuel L. (org.). Elements of reason: cognition, choice, and the bounds of rationality. Cambridge: Cambridge University Press, 2000. p. 47-66.

LUSKIN, Robert C.; FISHKIN, James S.; JOWELL, Roger. Considered opinions: deliberative polling in Britain. British Journal of Political Science, v. 32, p. 455-487, 2002.

MANZA, Jeff; COOK, Fay Lomax. The impact of public opinion on public policy: the State of the debate. In: MANZA, JEFF; COOK, Fay Lomax; PAGE, Benjamin I. (org.). Navigating public opinion: polls, policy, and the future of American democracy. [S.I.]: Oxford University Press, 2002. p. 17-32.

MARques, Ângela C. S. A deliberação a longo prazo no espaço de visibilidade mediada: o Bolsa-Família na mídia impressa e televisiva. Estudos em Jornalismo e Mídia, v. 7, n. 2, p. 273-285, 2010.

MARques, Ângela C. S.; MAIA, Rousiley C. M. Deliberation and political socialization: poor women discuss published opinios about Brazilian income transfer program. In: MAIA, Rousiley C. M. Deliberation, the media and political talk. New York: Hamptom Press, 2012. p. 227-254.

MoY, Patricia; DOMKE, David; STAMM, Keith. The spiral of silence and public opinion on affirmative action. Journalism and Mass Communication Quarterly, v. 78, n. 1, p. 7-25, 2001. 
Nelson, Thomas E.; Bryner, Sarah M.; Carnahan, Dustin M. Media and Politics. In: DRUCKMAN, James N. et al. (org.). Cambridge handbook of experimental Political Science. [S.I.]: Cambridge University Press, 2011. p. 201-214.

Noelle-Neumann, Elisabeth. Pesquisa eleitoral e clima de opinião. Opinião Pública, v. 1, n. 2, p. 47-62, dez. 1993.

NYHAN, Brendan; REIFLER, Jason. When corrections fail: the persistence of political misperceptions. Political Behavior, v. 32, p. 303-330, 2010.

PAGE, Benjamin I.; SHAPIRO, Robert Y. The rational public: fifty years af trends in Americans' policy preferences. 1. ed. Chicago: The University of Chicago Press, 1992.

POPKIN, Samuel L. Information shortcuts and the reasoning voter. In: GROFMAN, Bernard (org.). Information, participation and choice: an economic theory of democracy in perspective. Ann Arbor: The University of Michigan Press, 1993. p. 17-35.

POPKIN, Samuel L. The reasoning voter: communication and persuasion in presidential elections. 2. ed. Chicago and London: The University of Chicago Press, 1991.

PORTO, Mauro. Enquadramentos da midia e política. In: RUBIM, Antonio Albino Canelas (org.). Comunicação e política: conceitos e abordagens. Salvador: Editora UFBA, Editora Unesp, 2004. p. 73-104.

PORTO, Mauro. Televisão e política no Brasil: a Rede Globo e as interpretações da audiência. Rio de Janeiro: e-papers, 2007.

RedlaWsK, David P.; Tolbe RT, Caroline J.; Franko, William. Voters, emotions, and race in 2008: Obama as the first black president. Political Research Quarterly, v. 63, n. 4, p. 875-889, 2010.

Rego, Walquiria Leão; PInZANI, Alessandro. Vozes do Bolsa Família: autonomia, dinheiro e cidadania. São Paulo: Editora Unesp, 2013.

SCHEUfELE, Dietram A.; MoY, Patricia. Twenty-five years of the spiral of silence: a conceptual review and empirical outlook. International Journal of Public Opinion Research, v. 12, n. 1, p. 1-28, 2000.

SKOCPOL, Theda. Sustainable social policy: fighting poverty without poverty programs. The American Prospect, n. 2, p. 58-70, 1990.

SKOCPOL, Theda. Targeting within universalism: politically viable policies to combat poverty in the United States. In: JenCKS, Christopher; PETERSON, Paul E. (org.). The urban underclass. Washington, D.C.: Brookings Institution, 1991. p. 411-436.

StREB, Matthew J. et al. Social desirability effects and support for a female American president. Public Opinion Quarterly, v. 72, n. 1, p. 76-89, 2008.

Tourangeau, Roger; YAN, Ting. Sensitive questions in surveys. Psychological Bulletin, v. 133, n. 5, p. 859-883, 2007.

TURgeon, Mathieu; ChaVeS, Bruno Sant'Anna; WIVES, Willian Washington. Políticas de ação afirmativa e o experimento de listas: o caso das cotas raciais na universidade brasileira. Opinião Pública, v. 20, n. 3, p. 363-376, 2014. 
TURGEON, Mathieu; RENNó, Lucio. Informação política e atitudes sobre gastos governamentais e impostos no Brasil: evidências a partir de um experimento de opinião pública. Opinião Pública, v. 16, n. 1, p. 143-159, 2010.

VIDIGAL, Robert. Affirmative action attitudes of whites: evidence from a list experiment survey in Brazil. Brazilian Political Science Review, v. 12, n. 2, p. 1-31, 2018.

WILLIAMS, Richard. Using the margins command to estimate and interpret adjusted predictions and marginal effects. Stata Journal, v. 12, n. 2, p. 308-331, 2012.

WOOD, Wendy; RHODES, Nancy; BIEK, Michael. Working knowledge and attitude strength: an information-processing analysis. In: PETTY, Richard E.; KROSNICK, Jon A. (org.). Attitude strength: antecedents and consequences. Mahwah, New Jersey: Lawrence Erlbaum Associates, 1995. p. 283-313.

ZALLER, John R. The nature and origins of mass opinion. 13. ed. Cambridge: Cambridge University Press, 1992.

\section{Pedro Santos Mundim}

Universidade Federal de Goiás (UFG). Doutor em Ciência Política pelo Instituto Universitário de Pesquisas do Rio de Janeiro (IUPERJ). Mestre em Comunicação Social pela Universidade Federal de Minas Gerais (UFMG). Professor Associado de Ciência Política da Faculdade de Ciências Sociais da Universidade Federal de Goiás (UFG). psmundim@

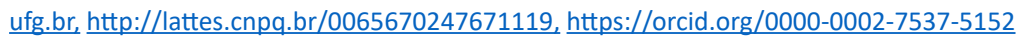

\section{Robert Vidigal}

Stony Brook University. Doutorando na State University of New York - Stony Brook. Mestre e Bacharel em Ciência Política pela Universidade de Brasília (UnB). robertleehc@gmail.com, http://lattes.cnpq.br/5924057455894001

\section{Fernando Canto Michelotti}

Ministério da Saúde (MS). Mestre em Sociologia pela Universidade Federal do Rio Grande do Sul (UFRGS). fcmichelotti@gmail.com http://lattes.cnpq.br/5078987445358582

\section{André Jácomo de Paula Pinto}

Instituto Brasileiro de Pesquisa e Análise de Dados (lbpad). Mestre e bacharel em Ciência Política pela Universidade de Brasília (UnB). Professor Assistente de Ciência Política do Centro Universitário do Distrito Federal (UDF). jacomo. andre@gmail.com, http://lattes.cnpq.br/9993666401671115 